\title{
Endoscopic removal of eroded adjustable gastric band in a pregnant patient
}

\author{
David C. Gochnour ${ }^{1}$, Brad E. Snyder ${ }^{1}$, Erik B. Wilson ${ }^{1}$, Peter A. Walker ${ }^{1}$, Shinil K. Shah ${ }^{1,2}$ \\ ${ }^{1}$ Departments of Surgery, University of Texas Medical School at Houston, Houston, ${ }^{2}$ Michael E. DeBakey Institute for Comparative \\ Cardiovascular Science and Biomedical Devices, Texas A and M University, College Station, TX, USA
}

\begin{abstract}
Complications of the laparoscopic adjustable gastric band, including erosion, have been well described. Increasingly, endoscopic techniques are being utilized to manage complications of this and other weight loss procedures. The authors presented what was believed to be one of the first reported cases of successful endoscopic removal of an eroded gastric band during pregnancy. A complete description of the case and review of the relevant literature is provided. Endoscopy for management of eroded adjustable gastric bands needs to be part of the armamentarium of surgeons and endoscopists who deal with complications of weight loss surgery.

Key words Adjustable gastric band, endoscopy, pregnancy
\end{abstract}

\section{Introduction}

The laparoscopic adjustable gastric band has been utilized for over 20 years since first described by Kuzmak in 1986. ${ }^{[1]}$ One complication associated with this procedure is band erosion. The reported incidence of erosion is approximately $0.1-3.7 \%$, with lower rates reported after the adoption of the pars flaccida technique for placement as well as the improved design of the newer generation of gastric bands. ${ }^{[2]}$ Endoscopic removal of eroded adjustable gastric bands have been described in the literature; in this report, we describe what was believed to be one of the first successful cases of endoscopic removal of an eroded adjustable gastric band in a gravid patient.

\section{Case Report}

A 28-year-old woman who was approximately 26 weeks pregnant, presented to an outside hospital secondary to

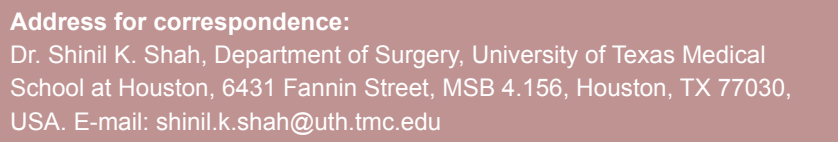

\begin{tabular}{|l|c|}
\hline \multicolumn{2}{|c|}{ Access this article online } \\
Website: & Quick Response Code \\
www.jdeonline.in & \\
DOI: &
\end{tabular}

several days of right upper quadrant abdominal pain. She was afebrile and tachycardic (low 100s). She had a leukocytosis of $15.7(\mathrm{~K} / \mathrm{cmm})$ with $83 \%$ neutrophils and an ultrasound demonstrating gallstones. Liver function tests demonstrated an elevated alkaline phosphatase (154 units/L) but were otherwise normal. She had a laparoscopic adjustable band placed approximately 8 years prior to the presentation. She had reported the band was unfilled at the beginning of her pregnancy. She previously had a cyst removed from her chest; otherwise the rest of her medical history was unremarkable. Magnetic resonance imaging of the abdomen and pelvis did not reveal any other etiologies for her abdominal pain.

Secondary to continued leukocytosis and pain, she was taken to the operating room for laparoscopic cholecystectomy. Intraoperatively, purulent fluid was noted around the adjustable gastric band tubing; this was aspirated, and a drain was placed. Esophagogastroduodenoscopy performed the following day revealed evidence of the erosion of the adjustable gastric band [Figure 1]. She was transferred to our facility for management (postoperative day [POD\#3] after cholecystectomy).

This is an open access article distributed under the terms of the Creative Commons Attribution-NonCommercial-ShareAlike 3.0 License, which allows others to remix, tweak, and build upon the work non-commercially, as long as the author is credited and the new creations are licensed under the identical terms.

For reprints contact: reprints@medknow.com

How to cite this article: Gochnour DC, Snyder BE, Wilson EB, Walker PA, Shah SK. Endoscopic removal of eroded adjustable gastric band in a pregnant patient. J Dig Endosc 2015;6:126-9. 


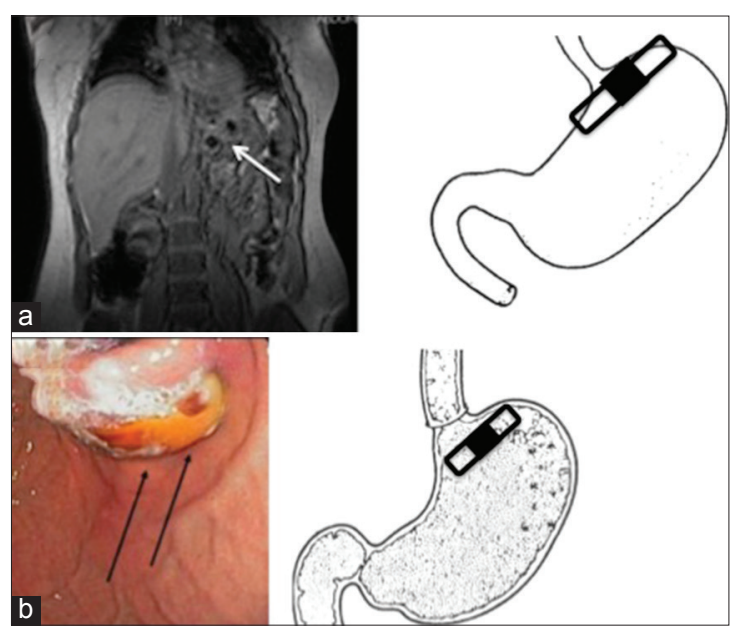

Figure 1: (a) Representative image from magnetic resonance imaging done prior to cholecystectomy. Band is noted in a good position. (b) Endoscopy performed demonstrated erosion (arrows) of the adjustable gastric band into the stomach. Portions of the diagram adapted from the National Institute of Diabetes and Digestive and Kidney Diseases, National Institutes of Health Image Library

The patient admitted to one previous episode of similar pain about 1-month prior to the presentation that resolved without intervention. She reported no previous issues with her adjustable gastric band and reported an approximately 60-pound weight loss at her lowest weight.

She was taken to the operating room, and diagnostic laparoscopy was performed. She had a profound ileus, which limited visualization; however, no purulent fluid or gastric contents were seen in the abdominal cavity. An endoscopic examination confirmed erosion of the adjustable gastric band. A Jagwire was passed around the band and then passed into an out of scope mechanical lithotriptor (Soehendra Lithotriptor, Cook Medical, Bloomington, IN) [Figure 2]. The band was cut. The cut edge of the band was grasped with a cold snare, and gentle traction completed the erosion into the lumen. An incision was made over the subcutaneous band port; the port was dissected free. The port and associated tubing was pulled out of the abdominal cavity until resistance was felt; the tubing was cut. The gastric band and small amount of associated tubing were then removed from the stomach. Complete removal of all components of the adjustable gastric band was confirmed.

The patient had a rapid resolution of her ileus, symptoms, and leukocytosis after band removal. Her intra-abdominal drain placed at the initial operation was removed. She was discharged in good condition on POD\#4 (after band removal). Pathology from the original cholecystectomy revealed findings consistent with chronic cholecystitis and cholelithiasis. The remainder of her pregnancy was uncomplicated; she delivered at 40 weeks.

\section{Discussion}

Morbid obesity negatively impacts fertility in women of reproductive age through multiple mechanisms. Weight loss achieved after bariatric surgery helps to restore reproductive hormonal balance and promotes fertility. ${ }^{[3,4]}$ Multiple studies have demonstrated the safety of pregnancy in patients who have previously undergone adjustable gastric banding; many of which have demonstrated improved fetal outcomes as compared to pregnancies in obese women. ${ }^{[5-7]}$ Given the known incidence of complications related to adjustable gastric bands, physicians should anticipate caring for gravid patients with complications related to gastric bands. In our report, we presented a patient who suffered an erosion of her gastric band during pregnancy. Gastric band erosion into the stomach was first described in 1998 by Weiner et al. ${ }^{[8]}$

Egberts et al. published a systematic review of the literature reporting band erosions. ${ }^{[9]}$ They found that patients presented most commonly with symptoms related to weight regain and decreased restriction. Many present with port site infections. Rarely, patients may present with an acute abdomen and peritonitis. They reported 231 erosions in 15,775 patients $(1.46 \%)$. The incidence varied greatly between reports (0.23-32.65\%) and most commonly occurred 12 months after band placement. Erosions were most closely correlated with surgeon experience. In another review by Singhal et al. in $2010,{ }^{[2]}$ erosion was most closely correlated with the perigastric method of band placement relative to the now standard practice of placement through the pars flaccida.

Various treatment strategies have been presented in the literature; most commonly laparoscopic or open approaches with band removal and subsequent repair of the gastric perforation. The laparoscopic approach involves intra-abdominal dissection and division of the port tubing, followed by dissection and transection of the gastric band. After its completion, the band is removed from around the stomach. Generally, an intraoperative leak test and/or a postoperative gastrografin upper gastrointestinal series is performed to evaluate for leak prior to begin the patient on a liquid diet. ${ }^{[10,11]}$ This approach is most often indicated when there is an erosion of a small portion of the adjustable gastric band.

In cases where the band has significantly migrated into the gastric wall, a gastrotomy may be necessary to remove the band. Hybrid laparoscopic/endoscopic or totally endoscopic approaches for removal of eroded gastric bands are becoming increasingly popular. ${ }^{[1-24]}$ The subcutaneous port and associated tubing is removed through a local incision. Upper endoscopy is then performed to locate the intraluminal portion of the eroded gastric band. The band is cut and then removed transorally. Different endoscopic devices have been utilized to cut the band. The Gastric Band Cutter (AMI, Feldkirch, Austria) has been used with success in multiple series. ${ }^{[11,13-15]}$ The device includes a cutting wire that is passed around the band and brought out with the endoscope. An external metal tube is then placed over the free ends and cinched down to the band. The ends of cutting wire are then introduced into a tourniquet device that is tightened by hand until the band is cut. ${ }^{[14]} \mathrm{A}$ cutting wire and mechanical lithotriptor can also be used, as was in our case. ${ }^{[20]}$ 

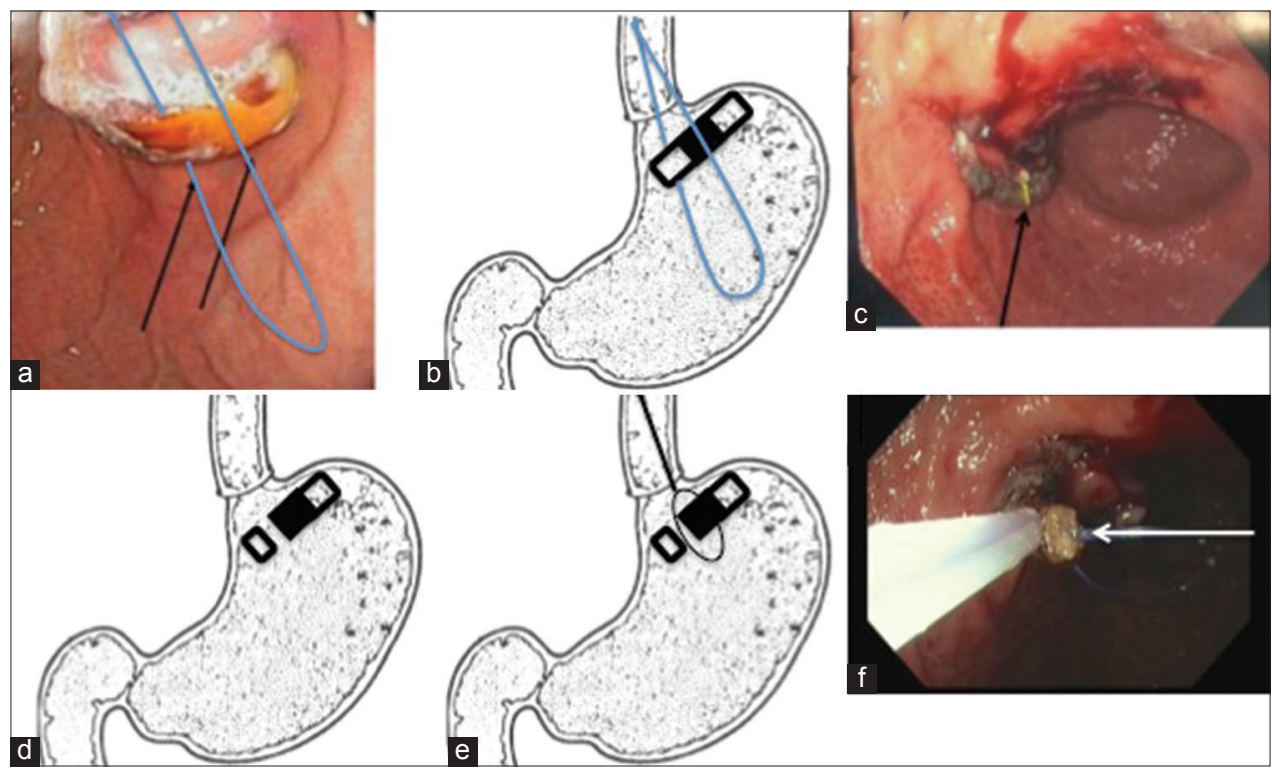

Figure 2: ( $a$ and b) For complete removal of the band, a Jagwire is passed around the band using a flexible endoscope, as depicted in $a, b$, and c. (c) Is a representative endoscopic view of the appearance of the Jagwire around an eroded gastric band. The Jagwire is then passed into an out of mouth mechanical lithotriptor. Representative image of an endoscopic picture of Jagwire (arrow) passed around an eroded gastric band. The Jagwire (arrow) is passed into an out of scope mechanical lithotriptor to cut the band. The cut band is then grasped using an endoscopic snare (d-f) to complete the removal. Portions of the diagram adapted from the National Institute of Diabetes and Digestive and Kidney Diseases, National Institutes of Health Image Library

There is a small but growing experience with endoscopic removal of both fixed and adjustable gastric bands. For adjustable gastric bands, the procedure is most successful when the buckle of the band has eroded intragastrically. ${ }^{[13]}$ Currently, there are $<150$ successful reports of endoscopic removal of eroded adjustable gastric bands. In most cases, the procedure is associated with high success rates.

To our knowledge, our report is the first of successful endoscopic removal of an eroded gastric band in a pregnant patient. While the adjustable gastric band is generally regarded as safe in pregnant patients, a small proportion will still experience the known complications, including band erosion. We report one of the first successful cases of successful endoscopic treatment of an eroded adjustable gastric band in pregnancy. Surgeons who encounter this patient population should be familiar with an endoscopic approach of band removal to decrease the invasiveness of the procedure and to minimize complications.

\section{Financial support and sponsorship Nil.}

\section{Conflicts of interest}

There are no conflicts of interest.

\section{References}

1. Kuzmak L. Silicone gastric banding: A simple and effective operation for morbid obesity. Contemp Surg 1986;28:13-8.

2. Singhal R, Bryant C, Kitchen M, Khan KS, Deeks J, Guo B, et al. Band slippage and erosion after laparoscopic gastric banding: A meta-analysis.
Surg Endosc 2010;24:2980-6.

3. Merhi ZO. Impact of bariatric surgery on female reproduction. Fertil Steril 2009;92:1501-8.

4. Musella M, Milone M, Bellini M, Sosa Fernandez LM, Leongito M, Milone F. Effect of bariatric surgery on obesity-related infertility. Surg Obes Relat Dis 2012;8:445-9.

5. Longitudinal Assessment of Bariatric Surgery (LABS) Consortium, Flum DR, Belle SH, King WC, Wahed AS, Berk P, et al. Perioperative safety in the longitudinal assessment of bariatric surgery. $N$ Engl J Med 2009;361:445-54.

6. O'Brien PE, MacDonald L, Anderson M, Brennan L, Brown WA. Long-term outcomes after bariatric surgery: Fifteen-year follow-up of adjustable gastric banding and a systematic review of the bariatric surgical literature. Ann Surg 2013;257:87-94.

7. Carelli AM, Ren CJ, Youn HA, Friedman EB, Finger AE, Lok BH, et al. Impact of laparoscopic adjustable gastric banding on pregnancy, maternal weight, and neonatal health. Obes Surg 2011;21:1552-8.

8. Weiner R, Emmerlich V, Wagner D, Bockhorn H. Management and therapy of postoperative complications after "gastric banding" for morbid obesity. Chirurg 1998;69:1082-8.

9. Egberts K, Brown WA, O’Brien PE. Systematic review of erosion after laparoscopic adjustable gastric banding. Obes Surg 2011;21:1272-9.

10. Nocca D, Frering V, Gallix B, de Seguin des Hons C, Noël P, Foulonge MA, et al. Migration of adjustable gastric banding from a cohort study of 4236 patients. Surg Endosc 2005;19:947-50.

11. Lattuada E, Zappa MA, Mozzi E, Fichera G, Granelli P, De Ruberto F, et al. Band erosion following gastric banding: How to treat it. Obes Surg 2007;17:329-33.

12. Weiss H, Nehoda H, Labeck B, Peer R, Aigner F. Gastroscopic band removal after intragastric migration of adjustable gastric band: A new minimal invasive technique. Obes Surg 2000;10:167-70.

13. Chisholm J, Kitan N, Toouli J, Kow L. Gastric band erosion in 63 cases: Endoscopic removal and rebanding evaluated. Obes Surg 2011;21:1676-81.

14. Neto NP, Ramos AC, Campos JM, Murakami AH, Falcao M, Moura EH, et al. Endoscopic removal of eroded adjustable gastric band: Lessons learned after 5 years and 78 cases. Surg Obes Relat Dis 2010;6:423-7.

15. Dogan ÜB, Akin MS, Yalaki S, Akova A, Yilmaz C. Endoscopic 
management of gastric band erosions: A 7-year series of 14 patients. Can J Surg 2014;57:106-11.

16. Campos JM, Evangelista LF, Galvão Neto MP, Ramos AC, Martins JP, dos Santos MA Jr, et al. Small erosion of adjustable gastric band: Endoscopic removal through incision in gastric wall. Surg Laparosc Endosc Percutan Tech 2010;20:e215-7.

17. Regusci L, Groebli Y, Meyer JL, Walder J, Margalith D, Schneider R. Gastroscopic removal of an adjustable gastric band after partial intragastric migration. Obes Surg 2003;13:281-4.

18. Dogan ÜB, Akova A, Solmaz S, Aydin M. Gastroscopic removal of a migrated adjustable gastric band: A case report. Turk J Gastroenterol 2010;21:297-301.

19. Baldinger R, Mluench R, Steffen R, Ricklin TP, Riedtmann HJ, Horber FF. Conservative management of intragastric migration of Swedish adjustable gastric band by endoscopic retrieval. Gastrointest Endosc
2001;53:98-101.

20. Christiaens P, Bossuyt P, Cuyle PJ, Moons V, Van Olmen A. Endoscopic removal of a transgastric eroded laparoscopic adjustable silicone gastric band. Gastrointest Endosc 2015;81:457-8.

21. Meyenberger C, Gubler C, Hengstler PM. Endoscopic management of a penetrated gastric band. Gastrointest Endosc 2004;60:480-1.

22. Blero D, Eisendrath P, Vandermeeren A, Closset J, Mehdi A, Le Moine $\mathrm{O}$, et al. Endoscopic removal of dysfunctioning bands or rings after restrictive bariatric procedures. Gastrointest Endosc 2010;71:468-74.

23. De Palma GD, Formato A, Pilone V, Rega M, Giuliano ME, Simeoli I, et al. Endoscopic management of intragastric penetrated adjustable gastric band for morbid obesity. World J Gastroenterol 2006;12:4098-100.

24. Coskun H, Bozkurt S, Atak T, Kadioglu H. Endoscopic management of penetrated adjustable gastric band with its connecting tube: Report of a case. Obes Facts 2011;4:244-7. 